Journal of Social Sciences 5 (4): 401-407, 2009

ISSN 1549-3652

(C) 2009 Science Publications

\title{
The Attitudes of Instructors and Faculty Members about the Quality of Technical Education Programs in Community Colleges in Jordan
}

\author{
${ }^{1}$ Ayman Suliman Mazahreh, ${ }^{1}$ Heba Hammad and ${ }^{2}$ Hanna Abu-Jaber \\ ${ }^{1}$ Department of Applied Science, Al-Balqa Applied University, \\ Princes Alia University College, P.O. Box 941941, Amman 11194, Jordan \\ ${ }^{2}$ Department of Basic Sciences, Faculty of Engineering Technology, \\ Al-Balqa Applied University, Jordan
}

\begin{abstract}
Problem statement: This study aimed to answer the question: What are the attitudes of the members of the study towards the technical education programs in the university colleges in accordance with sex, type of work, years of experience and scientific qualification in Jordan? Approach: The study sample consisted of 179 individuals (100 males and 79 females). A performance average of the sample members of the study was employed depending on the quality measure of the technical education in Jordan, and consisted of 62 paragraphs in 2009. The performance averages of the study members were extracted in the scale paragraphs depending on gender, type of college, type of work, scientific qualification and years of experience. A t-test was also carried out to measure sex variables, type of college and type of work. A variance analysis of average performance was made on the scientific qualification variables and years of experience. Results: The result of the differences in average performance regarding type of college was an indicator on all aspects and on the scale as a whole for the benefit of the private colleges, where the average performance of individuals on the scale as a whole was 2,947-3,396 for government colleges, which is a neutral indication among individuals and 3,4519-3,7203 for private colleges. These results demonstrate a positive sign for all areas and on the scale as a whole. The study found out that the difference in average performance by gender is not an indicative on the scale as a whole, as the average performance for males was 3,3132 while it was 3,2863 for females. The study also showed that the attitudes of the study members whose years of experience were 1-4 have positive attitudes on the scale as a whole, while those whose years of experience were 5-9 and 10-14 or more than 15, their attitudes on the scale as a whole were neutral. Conclusion/Recommendations: Regarding the attitudes of the study members by the scientific qualification, the study found out that holder of diploma, BA and MA degrees showed neutral attitudes on the scale, while Ph.D. holders demonstrated positive attitudes on the scale as a whole. In general, the difference in performance in the study was positive in planning while it was neutral in the rest of the aspects on the scale as a whole.
\end{abstract}

Key words: Attitudes, technical education, Jordan

\section{INTRODUCTION}

Technical and vocational education is formal education which includes educational preparation and behavior orientation and the transmission of manual skills and practical ability and scientific knowledge appropriate to business requirements. It basically aims at preparing technical workforce on which the responsibility of operating, production and maintenance falls upon and is characterized by its close relation with the needs of economic and social activity and trends in technological development witnessed by the community, putting its responsibility to respond rapidly to changing market needs of the workforce and technical skills in order to achieve the aspirations of the community towards development and continuous progress, in addition to a lot of goals that have emerged in the light of development in the existing technical and vocational education and modern technology. This study aimed to identify the attitudes of the study members about trends in technical education programs in colleges and universities in Jordan and to highlight the means and prospects for its development in the future.

Corresponding Author: Ayman S. Mazahreh, Department of Applied Science, Al-Balqa Applied University, Prince Alia'a University College, P.O. Box 941941, Amman 11194, Jordan 
Origins of technical education in Jordan-as is the case in most Arab states-go back to the last third of the twentieth century, when specialized universities, colleges, institutes and polytechnics were established at the level of technical diploma and certificate equivalent in terms of rights and privileges to those of the universities. That was a step advanced to the other at the postgraduate level in technical subjects, to produce qualified and trained cohorts in various fields, which effectively contributed to the management of the wheel of development ${ }^{[2,3]}$. Attitudes are important elements influencing the individual behavior and motivations. They are "one of the cases of preparedness and actual preparedness and nervous system organized by the experience and have an impact in guiding the individual responses to things and different positions".

As a result of the individual exposure to cues and stimuli in the external environment, they will affect him through the adoption process towards a specific and important things that lead to the formation and composition of the trends of individuals to satisfy needs and desires, personal experiences, personal factors, society and family.

The trends have a set of properties and most important of them are educated, connected with feelings and emotions, subject to change and characterized by relative stability.

Technical education is defined by the UNESCO as: "an education which is designed for senior secondary stage and the first undergraduate to prepare members of the middle level of employment and at the end of the university to prepare engineers and technologists to higher administrative positions and includes general education, technical education and theoretical and practical studies and technology and training the relevant skills. The stages of technical education may vary substantially by type of employment to be prepared and the level of education" ${ }^{\text {"[4] }}$.

Jordan interest in technical education emerged through the contents of the first paragraph of Article (3) of the Higher Education Act of the definition of "professional job is to prepare trained manpower in the technical level in the fields of industry, agriculture and services to meet the needs of society and development, by providing students the theory and practical knowledge, practical skills, practical values, attitudes and sound work habits, enabling them to carry out the occupations that they are specialized in by being aware of their nature and insights into the stages and results accurately and economically, safety and speed, as well as the social development of their competence ${ }^{[1]}$ ".

The researchers define the attitudes towards technical education as a collection of thoughts, feelings, perceptions and beliefs about technical education and the use of modern methods, which guide the behavior of the individual and determine his position on the subject. There is a need to develop the creative capabilities of students and workers in the area of work. As there are no studies about the capabilities of creative industry workers and their relationship to their attitudes toward modern technology, the need is more urgent than ever to develop the creative abilities and positive attitudes towards technology among workers in the field of industry. This will enable our Arab society to transform from a consumer and importer of foreign technology to a community that can benefit from and absorb in the building of national technology that suits our needs and capabilities and at the same time be able to grow and progress. Hence the importance creating positive attitudes towards technology on the grounds that attitude means "psychological tendency expressed by the evaluation of a particular topic, more or less of a preference or non-preference. The evaluation refers to cognitive preferential responses, emotional and behavioral, either expressed or implied" ${ }^{, 5]}$. Thus, the attitudes are tendencies, educated and implicit, of preferential responses that can be inferred from the behavioral tendencies to the approach or avoidance and the preference or lack of preference for the theme of attitude $^{[6-8]}$.

Importance of the study: The population of the Hashemite Kingdom of Jordan, according to estimates for 2003 is (5.480) million, of which the population under the age of (20) years old accounted for almost $54 \%$ and the population growth rate is $2.8 \%$.

The number of students in general education is 1515.3 thousand students for the academic year 2003/2004, including 1335.5 thousand in basic education, while secondary-school students have numbered 179.8 thousand, including 132.0 thousand students in the scientific and literary sections, an increase of $73.6 \%$ of the students in secondary education and the rest $(26.4 \%)$ in vocational education.

These statistics indicate that the priority has formerly been given to the academic education at the expense of technical and vocational education, which provides the associated disciplines with the needs of the Jordanian labor market. These statistics highlight the importance of this research to identify the conditions of technical and vocational education and to make recommendations and appropriate mechanisms to ensure the harmonization between education policies and technical and vocational education and the actual needs of the labor market through the answer to the question "What are the attitudes of the study members 
towards technical education programs in colleges and universities in accordance with sex, type of work, years of experience and scientific qualification in Jordan?

Aim of the study: This study aims at identifying the attitudes of teachers and instructors towards the reality of technical education in Jordan.

Questions of the study: What are the attitudes of the study members towards technical education programs in university colleges according to gender, type of work, years of experience and scientific qualification in Jordan?

Study sample: The study sample consisted of 179 members of the community colleges, two types of private and governmental colleges. The Table 1 and 2 show the classification of members of the study according to sex and type of work (Table 1).

From the Table 1 and 2, it can be shown that the number of the study members reached 179 (100 males and 79 females) from 7 governmental colleges (Irbid, Princess Alia, Engineering Technology, Salt, Amman, Rahmah and Zarqa) and 4 private colleges (Jerusalem, Arab Community, Naour and Arabic College).

Research procedure: A quality measure of technical education in Jordan, which was prepared by the researchers to measure the quality of technical education in Jordan was employed in this study. It consists of 62 paragraphs of which 11 paragraphs for the field of planning, 9 for the field of programs and curricula, 11 for the area of human resources/staff, 17 for the area of human resources/students and 14 in the area that supports the organization. The quality measure was tested to verify its validity and reliability through factor analysis of the key components of the measure. Its validity significances were extracted using Kronbach Alpha for each domain and the scale as a whole. The total scale reliability coefficient was (0.970) in a former published study. The average performance of the study members on this scale becomes a standard guide to the attitudes towards the quality of technical education in Jordan.

To answer the research question: What are the attitudes of the study members towards the programs of technical education in university colleges in accordance with gender, type of work, years of experience and scientific qualification in Jordan? The following steps were carried out:

- The averages of performance for the study members were derived to each scale of the paragraphs for each domain and the scale as a whole according to gender, type of college and type of work
Table 1: The distribution of faculty members and instructors by gender

\begin{tabular}{lclc}
\hline Type of university & Males & Females & Total number \\
\hline Governmental & 69 & 58 & 127 \\
Private & 31 & 21 & 52 \\
Total & 100 & 79 & 179 \\
\hline
\end{tabular}

Table 2: The distribution of the study members

\begin{tabular}{lcr}
\hline Study members & Number & \\
\hline Instructor & 59 & Valid \\
Teacher & 120 & \\
Total & 179 & \\
\hline
\end{tabular}

Table 3: The classification of individuals based on their average performance on the paragraphs to get to know their attitudes

Type of classification Range of degree

High negative attitude $1-1.8$

Negative attitude $\quad 1.81-2.6$

Neutral attitude 2.61-3.4

Positive attitude 3.41-4.2

High positive attitude $\quad 4.21-5$

- A t-test of gender, type of college and type of work variables was performed. A variance analysis for the averages of performance of the scientific qualifications and years of experience was also conducted

- Attitudes of the individuals were classified according to the median performance of the paragraphs in each area according to pentaclassification, where the length of the answer scale $(5-1=4)$ was divided on the required categories (5), to arrive at the length of the category $4 / 5=0.8$. And thus the individuals can be classified based on their averages of performance on the paragraphs to get to know their attitudes according to the Table 3.

\section{RESULTS}

In order to classify the attitudes of the study members, the length of the answer scale $(5-1=4)$ was divided on the number of categories required (5) to arrive at the length of the category $(5 / 4=0.8)$ and thus the individuals can be classified based on their average performance on the paragraphs to get to know their attitudes according to the Table 4 .

Independent samples test: By performing t-test on the averages of performance depending on the type of college, the differences in average performance were indicatives to all fields and on the scale as a whole for the benefit of the private colleges. The value of the average performance of the private colleges was (3.5763), while it was (3.1894) for the governmental colleges, as it is clear in Table 5. 


\section{J. Social Sci., 5 (4): 401-407, 2009}

Table 4: The average performance and standard deviation for each area as a result of the t-test analysis by type of college

\begin{tabular}{|c|c|c|c|c|}
\hline & \multicolumn{4}{|c|}{ Type of college } \\
\hline & \multicolumn{2}{|c|}{ Governmental } & \multicolumn{2}{|l|}{ Private } \\
\hline & Mean & SD & Mean & SD \\
\hline Planning & 3.3830 & 0.56118 & 3.7203 & 0.66558 \\
\hline Programs and curricula & 3.2231 & 0.76411 & 3.6624 & 0.70786 \\
\hline Human resources/faculty members & 3.3966 & 0.72571 & 3.5682 & 0.75587 \\
\hline Human resources/students & 2.9477 & 0.78183 & 3.5452 & 0.84589 \\
\hline Human resources & 3.1240 & 0.70307 & 3.5543 & 0.75809 \\
\hline Enterprise support & 3.1462 & 0.77674 & 3.4519 & 0.89245 \\
\hline College degree & 3.1894 & 0.61801 & 3.5763 & 0.70141 \\
\hline
\end{tabular}

Table 5: The average performance and standard deviation for each area based on t-test according to type

\begin{tabular}{|c|c|c|c|c|}
\hline & \multicolumn{4}{|l|}{ Gender } \\
\hline & \multicolumn{2}{|l|}{ Female } & \multicolumn{2}{|l|}{ Male } \\
\hline & Mean & SD & Mean & SD \\
\hline Planning & 3.4764 & 0.60464 & 3.4845 & 0.61915 \\
\hline Programs and curricula & 3.2743 & 0.76688 & 3.4111 & 0.77553 \\
\hline Human resources/faculty members & 3.4776 & 0.66238 & 3.4218 & 0.79279 \\
\hline Human resources/students & 3.0685 & 0.83755 & 3.1629 & 0.85029 \\
\hline Human resources & 3.2292 & 0.68530 & 3.2646 & 0.78967 \\
\hline Enterprise support & 3.2631 & 0.76424 & 3.2129 & 0.86701 \\
\hline College degree & 3.2873 & 0.60219 & 3.3132 & 0.71367 \\
\hline
\end{tabular}

Table 6: Performance attributable to gender

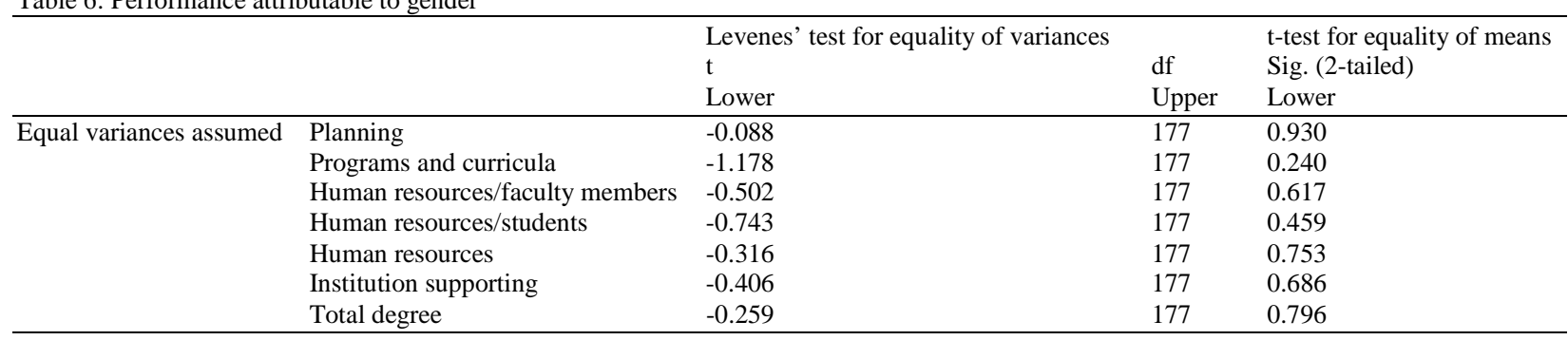

Table 7: The classification of the individual attitudes based on the average performance on each area depending on years of experience

\begin{tabular}{|c|c|c|c|c|c|c|c|c|}
\hline & \multicolumn{2}{|l|}{$1-4$ years } & \multicolumn{2}{|l|}{$5-9$ years } & \multicolumn{2}{|l|}{$10-14$ years } & \multicolumn{2}{|l|}{$>15$ years } \\
\hline & Mean & & Mean & & Mean & & Mean & \\
\hline & Upper bound & Classification & Upper bound & Classification & Upper bound & Classification & Upper bound & Classification \\
\hline Planning & 3.5627 & Positive attitude & 3.3927 & Positive attitude & 3.4976 & Positive attitude & 3.4518 & Positive attitude \\
\hline $\begin{array}{l}\text { Programs and } \\
\text { curricula }\end{array}$ & 3.5134 & Positive attitude & 3.3133 & Neutral attitude & 3.3216 & Neutral attitude & 3.1549 & Neutral attitude \\
\hline $\begin{array}{l}\text { Human resources/ } \\
\text { faculty members }\end{array}$ & 3.4530 & Positive attitude & 3.4345 & Positive attitude & 3.4545 & Positive attitude & 3.4435 & Positive attitude \\
\hline $\begin{array}{l}\text { Human resources/ } \\
\text { students }\end{array}$ & 3.2657 & Neutral attitude & 3.0165 & Neutral attitude & 3.2214 & Neutral attitude & 2.9109 & Neutral attitude \\
\hline Human resources & 3.3393 & Neutral attitude & 3.1807 & Neutral attitude & 3.3130 & Neutral attitude & 3.1201 & Neutral attitude \\
\hline $\begin{array}{l}\text { Institution } \\
\text { supporting }\end{array}$ & 3.3781 & Neutral attitude & 3.0986 & Neutral attitude & 3.1485 & Neutral attitude & 3.2900 & Neutral attitude \\
\hline Total degree & 3.4130 & Positive attitude & 3.2190 & Neutral attitude & 3.3098 & Neutral attitude & 3.2224 & Neutral attitude \\
\hline
\end{tabular}

By performing a t-test on the averages of performance by gender, the differences in average of performance were not indicative of all the areas and on the scale as a whole. The value of the average performance of males was (3.3132), while for females it was (3.2873) as shown in Table 6. This indicates that there were no differences in performance attributable to gender.

And based on the former classification it is noted that the average performance of individuals on the scale in the areas falls between $(2,947-3,396)$ for governmental colleges. This is an indicator of a neutral 


\section{J. Social Sci., 5 (4): 401-407, 2009}

Table 8: The classification of the attitudes of the individuals based on the average performance in each area depending on the scientific qualification

\begin{tabular}{|c|c|c|c|c|c|c|c|c|}
\hline & \multicolumn{2}{|c|}{ Medium diploma } & \multicolumn{2}{|l|}{ Bachelor } & \multicolumn{2}{|l|}{ Master } & \multicolumn{2}{|l|}{ Ph.D. } \\
\hline & Mean & & Mean & & Mean & & Mean & \\
\hline & Upper bound & Classification & Upper bound & Classification & Upper bound & Classification & Upper bound & Classification \\
\hline Planning & 3.2652 & Neutral attitude & 3.4991 & Positive attitude & 3.4773 & Positive attitude & 3.6303 & Positive attitude \\
\hline Programs and curricula & 3.0139 & Neutral attitude & 3.3962 & Neutral attitude & 3.3256 & Neutral attitude & 3.6000 & Positive attitude \\
\hline $\begin{array}{l}\text { Human resources/ } \\
\text { faculty members }\end{array}$ & 3.2992 & Neutral attitude & 3.4391 & Positive attitude & 3.4457 & Positive attitude & 3.5788 & Positive attitude \\
\hline Human resources/students & 2.9093 & Neutral attitude & 3.1321 & Neutral attitude & 3.1373 & Neutral attitude & 3.2333 & Neutral attitude \\
\hline Human resources & 3.0625 & Neutral attitude & 3.2527 & Neutral attitude & 3.2584 & Neutral attitude & 3.3690 & Neutral attitude \\
\hline Institution supporting & 3.3393 & Neutral attitude & 3.2345 & Neutral attitude & 3.1994 & Neutral attitude & 3.2381 & Neutral attitude \\
\hline Total degree & 3.1539 & Neutral attitude & 3.3131 & Neutral attitude & 3.2937 & Neutral attitude & 3.4194 & Positive attitude \\
\hline
\end{tabular}

Table 9: The results of the t-test according to the type of work (average performance and standard deviation for each area)

\begin{tabular}{|c|c|c|c|c|}
\hline & \multicolumn{4}{|c|}{ Type of job } \\
\hline & \multicolumn{2}{|l|}{ Instructor } & \multicolumn{2}{|l|}{ Teacher } \\
\hline & Mean & SD & Mean & SD \\
\hline Planning & 3.5285 & 0.67872 & 3.4576 & 0.57652 \\
\hline Programs and curricula & 3.3992 & 0.80946 & 3.3269 & 0.75611 \\
\hline Human resources/faculty members & 3.4761 & 0.84041 & 3.4318 & 0.68318 \\
\hline Human resources/students & 3.2164 & 0.91966 & 3.0745 & 0.80354 \\
\hline Human resources & 3.3184 & 0.82275 & 3.2149 & 0.70256 \\
\hline Institution supporting & 3.4431 & 0.83255 & 3.1327 & 0.79955 \\
\hline Total degree & 3.3956 & 0.72239 & 3.2556 & 0.63310 \\
\hline
\end{tabular}

attitude of the individuals in all the areas. However, the average performance of individuals among the private colleges was (3.4519-3.7203), which shows a positive indicator for all areas and on the scale in general.

The performance of the females on the paragraphs scale indicates a positive attitude on the areas of (planning-human resources/faculty members), while their attitudes were neutral in other areas on the scale as a whole.

While the average performance of males presented a positive attitude in the areas of (planning - programs and curricula-human resources/faculty members), their attitudes remained neutral in the rest of the areas, including the scale as a whole.

Table 7 shows the attitudes of the study members according to the years of experience in every sphere and on the scale as a whole. It was found that the tendencies of individuals with experience (1-4) were positive on the scale as a whole and on the areas of (planning, programs curricula and human resources/faculty members) and their attitudes were neutral on the rest of areas.

It can also be noted that the tendency of the members of the study experienced (5-9) was neutral to most areas and on the scale as a whole, but positive on the area of human resources/faculty members.

The case for those with experience of (10-14), their attitudes were neutral in most of the areas and on the scale as a whole, but positive to the areas of human resources/faculty members and planning.

The attitudes of those whose experience is (over 15) were also neutral in most of the areas and on the scale as a whole, but positive to the areas of human resources/faculty members and planning

Table 8 shows that the attitudes of the study members according to scientific qualification were different. Holders of diploma exhibited a neutral attitude to all fields and on the scale as a whole. Holders of MA and BA degrees exhibited a neutral attitude to most areas and on the scale as a whole, but a positive attitude on the areas of human resources/faculty members and planning.

$\mathrm{PhDs}$ also showed a positive attitude on the scale as a whole and on the areas of human resources/faculty members, planning, programs and curricula

It can be inferred from Table 9 that the attitudes of the study members with regard to the type of work were positive on the areas of human resources/faculty members and planning and neutral on the rest of areas and on the scale as a whole.

\section{DISCUSSION}

In general, it is clear from Table 11 that the attitude of the study members was positive on the area of planning and neutral in the rest of the fields and on the scale as a whole. 
J. Social Sci., 5 (4): 401-407, 2009

Table 10: The classification of the attitudes of the individuals based on the average performance on each area depending on the type of work

\begin{tabular}{|c|c|c|c|c|}
\hline & \multicolumn{4}{|l|}{ Type of job } \\
\hline & Instructor & Attitude & Teacher & \\
\hline & Mean & & Mean & \\
\hline Planning & 3.5285 & Positive attitude & 3.4576 & Positive attitude \\
\hline Programs and curricula & 3.3992 & Neutral attitude & 3.3269 & Neutral attitude \\
\hline Human resources/faculty members & 3.4761 & Positive attitude & 3.4318 & Positive attitude \\
\hline Human resources/students & 3.2164 & Neutral attitude & 3.0745 & Neutral attitude \\
\hline Human resources & 3.3184 & Neutral attitude & 3.2149 & Neutral attitude \\
\hline Institution supporting & 3.4431 & Positive attitude & 3.1327 & Neutral attitude \\
\hline Total degree & 3.3956 & Neutral attitude & 3.2556 & Neutral attitude \\
\hline
\end{tabular}

Table 11: The average performance of individuals on each area in general

\begin{tabular}{llll}
\hline & Number & Mean & SD \\
\hline Planning & 179 & 3.4810 & 0.61109 \\
Programs and curricula & 179 & 3.3507 & 0.77257 \\
Human resources/ faculty & 179 & 3.4464 & 0.73662 \\
members & & & \\
Human resources/students & 179 & 3.1213 & 0.84364 \\
Human resources & 179 & 3.2490 & 0.74359 \\
Institution supporting & 179 & 3.2350 & 0.82137 \\
College degree & 179 & 3.3018 & 0.66509 \\
Valid N (list wise) & 179 & & \\
\hline
\end{tabular}

Interpreting the results: In answering the research question which is concerned with the attitudes of the members of the study depending on the type of college, it was positive for those who work in private colleges, but it was neutral for those who work in governmental colleges. The average of performance in the governmental colleges was between (2.947-3.396) in general. This is a neutral attitude of the members in all the fields. The average performance in the private colleges was between (3.7203-3.4519), which indicates a positive attitude in all the fields and on the scale as a whole.

In studying the attitudes of the study members according to gender, the performance of the females on the items of the scale was an indicative of a positive attitude on the areas of (planning-human resources/faculty members), while their attitude was neutral in the other areas on the scale as a whole.

The study also revealed that the attitude of the males in the sample of study was positive in three areas (planning-programs, curricula and human resources/faculty members). However, their attitude remained neutral in the rest of the areas, including the scale as a whole.

The attitude of the study members with regard to type of work for both instructors and teachers was positive in all areas of the scale and on the scale as a whole, where the two agreed to a positive attitude on the areas of (planning and human resources/faculty members). Regarding their attitudes on the support of the institute, the instructors demonstrated a positive attitude, while the teachers manifested a neutral one.
In the analysis of the attitudes depending on the years of experience, the study indicated that there is a kind of agreement between the members of the study. They showed a neutral attitude on the areas of (human resources, human resources/students and supporting institution). The results also revealed that their attitudes towards (human resources/faculty members) were positive. However, the various years of experience groups showed a positive attitude on the area of planning, while class (5-9) showed a neutral attitude on the same domain. All groups of experience showed a positive attitude towards the area of programs and curricula except group (1-4), which demonstrated a neutral attitude on the same domain.

In general, all groups of experience manifested a neutral attitude on the scale as a whole and the group (1-4) showed a positive attitude in general.

As analyzing the attitudes according to the scientific qualification in the areas of the scale and on the scale as a whole, it was found out that diploma holders showed a neutral attitude in all the areas and on the scale as a whole. But all holders of BA and MA degrees demonstrated a positive attitude in the areas of (planning and human resources/faculty members) and a neutral one on the rest of the areas and on the scale as a whole.

Concerning the holders of Ph.D. degrees in the study, the results showed that they were positive in their attitude with regard to (planning, programs, curricula and human resources/faculty members), but neutral on the areas of (human resources/students, human resources and institution supporting). Generally, their attitude on the scale as a whole was positive.

\section{CONCLUSION}

In analyzing the average performance of the attitudes of the study members and in classifying these attitudes as it is illustrated in Table 10-12, the members of the study showed a positive attitude in the area of planning and a neutral one to the rest of the areas and on the scale as a whole. 
J. Social Sci., 5 (4): 401-407, 2009

Table 12: The classification of individuals based on the attitudes average performance on each area in general

\begin{tabular}{|c|c|c|c|c|}
\hline & Number & Mean & SD & Individual attitudes classification \\
\hline Planning & 179 & 3.4810 & 0.61109 & Positive \\
\hline Programs and curricula & 179 & 3.3507 & 0.77257 & Neutral \\
\hline Human resources/faculty members & 179 & 3.4464 & 0.73662 & Neutral \\
\hline Human resources/students & 179 & 3.1213 & 0.84364 & Neutral \\
\hline Human resources & 179 & 3.2490 & 0.74359 & Neutral \\
\hline Institution supporting & 179 & 3.2350 & 0.82137 & Neutral \\
\hline College degree & 179 & 3.3018 & 0.66509 & Neutral \\
\hline Valid N (list wise) & 179 & & & \\
\hline
\end{tabular}

\section{Recommendations:}

- Adopting studies that focus on the development of attitudes about technical education in all aspects and especially in the fields of programs, curricula and human resources, which is a strong supporter for it and for its institutions progress

- Adopting plans which contribute to supporting organizations working in technical education programs and human resources qualified by civil society organizations to bridge the cooperation between them

- Maintaining the positive attitudes among workers in technical education in Jordan to upgrade it to a high level of technical excellence in the era of information and technology we live in

\section{REFERENCES}

1. Al-Sheikh, O. et al., 1990. A Study of the Reality of Education in the Community Colleges in Jordan. Ministry of Higher Education, Amman. DOI: 10.1007/1-4020-4773-8

2. HongPong, 2003. A clean break: A new strategy for securing the realm. http://everything2.com/title/A+clean+break\%253A $+a+$ new+strategy+for+securing+the+realm
3. Michael Shinagel, 2006. Continuing higher education review.

http://www.ucea.edu/pdfs/cher/2006CHER.pdf

4. Eagley, A. and S. Chaiken, 1993. The Psychology of Attitudes. Jovanovich Inc., Harcourt Brace, CA., Orlando, FL.

http://www.geocities.com/ishawky2000/internetAtt .stud.htm

5. Sul Kassicieh, and Nabeel Rahal, 2007. A model for disruptive technology forecasting in strategic regional economic development. Technol. Forecast. Soc. Change, 74: 1718-1732. DOI: 10.1016/J.TECHFORE.2006.12.005

6. Parker, J., 1999. Computer anxiety and its relationships to age, gender, and Myers-Briggs personality. http://www.foryou.net /trend/thesis.htm

7. Psacharopoulos, George, 1994. Returns to investment in education: A global update. World Dev., 22: 1325-1343.

8. Slem, C.M., D.J. Levi and A. Young, 1995. Attitudes about the impact of technological change: Comparison of US and Japanese workers. J. High Technol. Manage. Res., 6: 211-228. DOI: 10.1016/1047-8310(95)90015-2 